Comparative Philosophy Volume 3, No. 2 (2012): 36-40

Open Access / ISSN 2151-6014

www.comparativephilosophy.org

CONSTRUCTIVE ENGAGEMENT DIALOGUE (2.4)

\title{
SOME THOUGHTS ON IDENTITY OF ISLAMIC PHILOSOPHY
}

\section{BO MOU}

I do not pretend to be an expert in Islamic philosophy that is the central subject of Dr. Mohammad Azadpur's book, and I have thus learnt a lot from his book. Although I am not qualified to comment on the details of the author's account concerning the distinct resources of Islamic philosophy, I would like to make several comments on some general points concerning the identity of Islamic philosophy with regard to the identity of philosophy, methodological strategy, and the relationship between philosophy and religion. With consideration of the critical-engagement purpose of the "constructive-engagement dialogue" section, these comments are critical in nature for the sake of further exploring some involved philosophically interesting questions.

According to Mohammad, if my understanding is correct, what is called 'Islamic philosophy' or 'Islamic Peripatetic (philosophical) tradition' referentially designates what Muslims inherited from the Greeks. So it is one key issue how to understand the identity of the philosophy by the Greeks. However, there are distinct modern readings or interpretations of the identity of Islamic Peripatetic philosophy (given that one literal sense of 'Peripatetic' is "of or pertaining to the Aristotelian school) or of what Muslims inherited from the Greeks. The author challenges "the standard, modernist interpretation of what Muslims inherited from the Greeks" and renders it involving "a fundamental misunderstanding" (7): "These modernist historians of Islamic philosophy consider Greek philosophy to be comprised of systems of rational knowledge formulated by different philosophers or schools of philosophy" (ibid.); the author adopts Pierre Hadot's interpretation to the effect that the Greeks saw philosophy primarily as the practice of spiritual exercises aimed at the transformation of the self and the acquisition of wisdom; the author intends to argue that "this is how 'Islamic' Peripatetic philosophers understood what they inherited from the Greeks" and thus that Islamic Peripatetic philosophy means "an Islamic practice of philosophical spiritual exercises". If so, then the next question is this: what has made Islamic way of the Greeks-style practice of philosophical spiritual exercises distinct and unique? The author argues that "what makes the philosophical way of life

MOU, BO: Professor of Philosophy, Center for Comparative Philosophy, San Jose State University, USA. Email: bo.mou@sjsu.edu 
advanced by Islamic philosophers unique is the appropriation of this Greek tradition into a legacy of Islamic prophetology" (ibid.). My subsequent comments focus on several metaphilosophical and methodological issues involved in the foregoing approach, in view of similar concerns in some other major philosophical tradition (Chinese philosophy, in this case).

1.

My first comment is on the philosophical identity of Islamic Peripatetic tradition. Many think that the critique (taking nothing absolutely immune from criticism and without blindly claiming anything) and justification (understood in a broad way) constitute two closely-related (prescriptive) defining features of philosophical inquiries in treating a series of fundamental issues, which might be jointly concerned by philosophy and religion. For those who subscribe to and maintain the foregoing crucial nature of philosophical inquiries, whether philosophy should be "the practice of spiritual exercises aimed at the transformation of the self and the acquisition of wisdom" or in "the production of abstract rational discourse" would not be a controversial issue; for such a type of critique/justification inquiries can be present in both kinds of activities. To this extent, and in this sense, those philosophers would agree with the author to his rejection of the account that takes philosophical activity merely or exclusively "as the production of abstract rational discourse"; they would also agree with the author to his inclusion of "the practice of spiritual exercises aimed at the transformation of the self and the acquisition of wisdom". For instance, this is true to many scholars in studies of Chinese philosophy, as classical Chinese philosophy (or philosophical "critique/justification" strands/parts of Chinese tradition of thought) is largely not the "professional" production of abstract rational discourse. However, given the foregoing prescriptive "critique/justification" character of philosophy (or if this understanding of the identity of philosophy is reasonable), for those who maintain the critique/justification nature of philosophy, what is really at issue would lie in the critique/justification character of Islamic philosophy, whether it is taken to be the activities and production of a systematic abstract rational discourse or the practice of spiritual exercises, whether one focuses on its "rational" layer or "imaginative" layer, and whether one pays more attention to its theoretical dimension or its practical dimension. Actually, both the production of the abstract rational theory account and the practice of spiritual exercises can go in distinct directions: either in the critical/justification direction or in the faith-based divinely direction. At this point, how to understand and appreciate the nature and features of the legacy of Islamic prophetology in Islamic Peripatetic tradition is one key indeed.

There is another concern about the author's characterization of the identity of Islamic philosophy in terms of an Islamic practice of spiritual exercises aimed at the transformation of the self and the acquisition of wisdom: it seems to be both too narrow (i.e., excluding what is expected to be included) and too broad (i.e., including what is not expected to be included) [or either the former case or the latter case for the consideration to be addressed]. Given that some products of abstract rational 
discourse, such as many resources in philosophy of language, philosophy of mathematics, etc., including those (if any) in Islamic Peripatetic tradition should not be excluded from the result of philosophical inquiry, they would be nevertheless excluded by the current characterization, as they were carried out without aiming at the transformation of the (moral or other dimensions of) self of their practitioners. On the other hand, many of those mental or "spiritual" exercises in other intellectual activities (such as some of those in math and science) do aim explicitly at improving or "transforming" the intellectual-capacity dimension of the self and the acquisition of human wisdom involved in those activities, given that such intellectual activities constitute one substantial dimension and layer of the human meaningful life; but they themselves are not philosophical inquiries due to the nature of the intellectual issues or topics under such exploration. One might object that the discourse of "the transformation of the self and the acquisition of wisdom" here is restricted to those concerning human morality; nevertheless, this would block one possible way-out modification for the former case (i.e., seeming to be too narrow).

2.

My second comment or question is related to one point of the foregoing comment: given that Islamic Peripatetic tradition includes the prophecy discourse as its crucial portion, how can one look at the due relationship between the critique/justification character of philosophical activities and the imagination power of prophecy? Should such imagination be regulated by adequate critique/justification or eventually be based on religious faith in God (in the Islamic sense of the term)? If the imagination power of prophecy is to be regulated by adequate critique/justification, then both can be compatible or even somehow mutually enhanced. If the imagination power of prophecy is supposed to be regulated merely or eventually by God or the absolute faith in God, one would further question the philosophical nature of Peripatetic tradition while acknowledging and appreciating the value of the prophecy.

It is true that, historically speaking, philosophy and religion were not separated from each other at earlier (or even recent) stages of development of various (culture/region-associated) philosophical traditions as writers (say, in ancient times) did not make the conceptual distinction between intellectual disciplines that we do; it is also true that some religion-related discourse (topics and resources) might be closely related to a philosophical movement in some traditions (for example, the current case concerning the prophecy discourse in Islamic philosophy). Nevertheless, this amounts to saying neither that there are no significant conceptual distinctions between those inquiries, nor that we cannot reflectively and effectively focus on one dimension of the whole in the subsequent reflective examination (say, its philosophical dimension) nor that we cannot creatively transform a historical religiously-oriented discourse into a philosophically-oriented discourse employing some relevant and philosophically interesting resources from the previous discourse. We can do that, depending on the primary purpose of a project in reflective examination. For one thing, if one's primary purpose is to examine how an idea or 
approach in one tradition could contribute to some philosophical issue together with some other approach (either from the same tradition or from another tradition) instead of just giving a historical description, then one is entitled to focus only on the philosophical dimension or even only on some aspect(s) of the philosophical dimension most relevant to the current concern. For another thing, scholars in contemporary studies of Islamic philosophy are indeed entitled to distinguish two kinds of prophecy discourse, i.e., (a) the (philosophically-oriented) prophecy discourse that is supposed to be regulated by adequate critique/justification, and (b) the (religiously-oriented) prophecy discourse that is supposed to be regulated merely or eventually by God or the absolute faith in God, even if it might be the case that the former prophecy discourse, (a), was not historically produced but is reflectively and creatively produced by contemporary scholarship in Islamic philosophy for the need of philosophical inquiry.

Applying that distinction to ancient Islamic materials reveals the similar degree of overlap and distinctiveness as it does to ancient Western materials or ancient Chinese materials, which also did not distinguish what we now call 'philosophy' from what is called 'natural philosophy' (incipient science) or what is called 'Chinese thought'. In keeping with this consideration, we can soundly and reflectively focus on the philosophical aspects and dimensions of texts that also have historical, literary or religious value and content. So nothing in this observation about Islamic thought prevents us from reflecting on the philosophical significance of an idea or approach in the tradition where its philosophical value and inferential connection with other concerns, issues, ideas or approaches could also be given a historical, literary or religious description. When providing the philosophical dimension, we legitimately focus one type of reflective interest or agenda in trying to understand one significant aspect of Islamic culture; we can do so without denying that other kinds of understanding and elaboration are possible. We have the conceptual resources to distinguish between thinkers, themes, ideas and arguments that are more or less philosophical or religious. Given our understanding of philosophical inquiry and how its methodology differs from a religious methodology, the overlap of subject matter and the fact that the methods are mixed does not prevent our highlighting and discussing the philosophical distinctions and reflecting on how the overlap might and might not be relevant to proper understanding of both ancient Islamic philosophy and religion. Indeed, for this reason, what is under our current focus is called 'Islamic philosophy' and not 'Islamic thought' or 'Islamic religion', given that we do not want to conceptually conflate them and take these labels simply as each other's nicknames or alternative titles. ${ }^{1}$

3.

My final question about which I would like to consult Mohammad is this: If the very

\footnotetext{
${ }^{1}$ For my earlier (more comprehensive) discussion of some general methodological points involved here, see Mou 2009, sections 1and 3.
} 
conception of Islamic philosophy is not limited to that of Islamic Peripatetic tradition but broadly includes all reflective activities or strands of critique/justification in treating various fundamental concerns in human moral or other intellectual life within the Islamic tradition (whether they are presented in "the practice of spiritual exercises aimed at the transformation of the self and the acquisition of wisdom" or in "the production of abstract rational discourse", and whether they occur in Islamic Peripatetic tradition or in some other Islamic movements of thought), what would result in from this conception of Islamic philosophy? Would this conception of Islamic philosophy result in damaging some core ideas of Islamic Peripatetic tradition or exclude some significant philosophical resources? Would this conception of Islamic philosophy be reflectively more constructive and philosophically more inclusive? [The case might be similar to that concerning the identity of Chinese philosophy in this connection: Chinese philosophy, as widely realized, intrinsically includes philosophical resources from diverse engaging movements of thoughts instead of, say, Confucian tradition only or even ancient (or classical) Chinese philosophy only, as one of the intrinsic defining features of Chinese philosophy lies in the critical engagement between its distinct parts (such as that between the Confucian and Daoist thinkers during the pre-Han period and that between the traditional Chinese philosophy and its contemporary critique). That is one of the sources where the critical while constructive potential of Chinese philosophy lies.]

Let me highlight the points of my foregoing comments in this way. I have no doubt about the philosophical nature of Mohammad's book: indeed, it seems to me that the author's book itself fits into the foregoing defining character of philosophy which has been characterized above. He presents a critique of certain understandings/interpretations of what Islamic philosophy is and makes an argument for a distinct account. One question is thus this: may one or should one apply these features to characterize the identity of Islamic philosophy, both at the level of the practice of spiritual exercises and at the level of the production of abstract rational discourse (whether within or beyond but still within the Islamic tradition)? In other words, can one say that reason and imagination in philosophy should be both unbound to any ad hoc activities/boundaries (say, "the production of abstract rational discourse") and should be bound in the sense that philosophical inquiries are to be subjected to and regulated by adequate critique and justification (whether they are in Western philosophy, in Chinese philosophy or in Islamic philosophy)?

\section{REFERENCES}

Azadpur, Mohammad (2011), Reason Unbound: On Spiritual Practice in Islamic Peripatetic Philosophy (Albany, NY: State University of New York Press).

Mou, Bo (2009), "On Some Methodological Issues Concerning Chinese Philosophy”, in History of Chinese Philosophy, ed. Bo Mou (London: Routledge), 1-39. 